\title{
MATE CHOICE AND POLYANDRY BENEFIT REPRODUCTION AND PROGENY FITNESS IN THE LADYBIRD HIPPODAMIA VARIEGATA (GOEZE)
}

\author{
AHMAD PERVEZ ${ }^{*}$ AND NAVODITA MAURICE ${ }^{2}$ \\ ${ }^{1}$ Biocontrol Laboratory, Department of Zoology, Govt. Degree College, Talwari-Tharali, Chamoli-246482, Uttarakhand, India, Phone: \\ 91-1363-277843 \\ ${ }^{2}$ Department of Biological Sciences, Sam Higginbottom Institute of Agriculture, Technology and Sciences, (Formerly Allahabad \\ Agricultural Institute), Deemed-to-be-University, Naini, Allahabad-211007, India \\ *Corresponding author: ahmadpervez@yahoo.com
}

\section{ABSTRACT}

The effect of mate choice and polyandry on the reproductive performance and progeny fitness of a predaceous ladybird, Hippodamia variegata Goeze, was studied. The following mating combinations were used: (i) virgin female paired with the same and initially unmated male once per day (monogamy with limited mating), (ii) virgin female paired once daily with an unmated male (polyandry with no mate choice) and (iii) virgin female kept with five unmated males (polyandry with mate choice), with the food in each case an ad libitum supply of Aphis craccivora. Polyandrous females that had a free choice of mates were significantly more fecund (585.50 \pm 13.80 eggs) and higher percentage of their eggs hatched $(95.32 \pm 1.99 \%)$ than was the case for polyandrous females with no choice of mates (495.20 \pm 14.25 eggs and $88.81 \pm 3.29 \%$ ) followed by monogamous females ( $405.00 \pm 16.20$ eggs and $83.13 \pm 2.07 \%)$. Thus, mate choice and multiple mating by females is advantageous in terms of progeny production. The larvae that hatched from the eggs laid by these females were reared to maturity and their survival, duration of development and fitness determined. The fitness of offspring of polyandrous females $(0.4787$ \pm 0.01 ) was better than that of polyandrous females that did not choose their mates $(0.4418 \pm 0.02)$ and monogamous $(0.4057 \pm 0.01)$ females. In addition, a greater percentage of the offspring of polyandrous females that chose their mates survived and developed faster than those of monogamous females with limited mating. These results reveal that polyandry with mate choice results in increased reproduction and better offspring quality. Hence, if one is interested increasing the production of $H$. variegata it is recommended that systems of production are developed that enable the females to be polyandrous and to select their mates.

Keywords: Hippodamia variegata, Mating, Coccinellidae, Reproduction, fecundity, hatchability

\section{Introduction}

Promiscuity, in terms of both polyandry and polygyny, is common in insects, especially ladybirds (Majerus 1994). It is assumed that promiscuity is advantageous for predaceous ladybirds (Omkar and Mishra 2005a). In particular, female fitness in terms of fecundity and that of her progeny increases when females mate with good quality males. The fertility of certain ladybirds, e.g. Adalia bipunctata Linnaeus, is maintained by promiscuity despite its high costs for females (Majerus 1994). However, certain ladybirds, e.g. Propylea dissecta (Mulsant), do not mate repeatedly or are promiscuous, as they only need to mate a few times to remain fertile throughout their life, with peak female fitness achieved after a few matings (Pervez 2002). The female fitness is expected to be at a maximum after a few matings if the costs of copulation outweigh any benefits. Such costs may include reduced longevity (Arnqvist and Nilsson 2000), ejaculate toxicity (Rice 1996), risk of predation or injury (Rowe 1994; Bonduriansky and Brooks 1998), loss of energy due to carrying males (Watson et al. 1998), loss of time available for foraging (Rowe 1994), or infection by parasites or pathogens (Daly 1978; Watson 1993).

Hippodamia variegata (Goeze) is one of the most abundant ladybirds in the hilly ecosystem of North India and feeds on many species of aphid infesting agricultural and horticultural crops. This Palaearctic eurytopic species has been successfully introduced into USA, Canada (Gordon 1987; Krafsur et al. 1996; Wheeler and Stoops 1996), Bulgaria (Natskova 1973), Ukraine (Gumovskaya 1985), Italy (Nicoli et al. 1995), and Turkmenistan (Belikova and Kosaev 1985). It makes up $64.5 \%$ of the total number of coccinellid individuals found on cotton infested with Aphis gossypii Glover in Greece (Kavallieratos et al. 2002). It also feeds on other sucking insects (Alan 1979) such as cicadellids (Singh et al. 1991) and the larvae of Curculionidae (Sadeghi and Esmailli 1992). The mating and reproductive behaviour of $H$. variegata has not been studied. Research on this species has mostly focussed on aspects of its predatory behaviour (Fan and Zhao 1988; Obrycki and Orr 1990; Kalushkov et al. 1991; Sadeghi and Esmailli 1992; Singh and Singh 1994). Hippodamia variegata is a medium sized ladybird, like $P$. dissecta, which does not need to mate repeatedly in order maximize its life time fertility. The hypothesis that polyandry is beneficial for female fitness was tested using $H$. variegata as the model species.

\section{Material and Methods}

\section{Stock Culture}

Adults of $H$. variegata were collected from agricultural fields at Talwari, Chamoli, North India, from beans, Doli- 
chos lablab Linnaeus, infested with Aphis craccivora Koch. They were paired in Petri dishes containing an ad libitum supply of A. craccivora on twigs of bean (D. lablab) plants and kept in an Environmental Test Chamber (REMI Instruments, India) at $25 \pm 2{ }^{\circ} \mathrm{C}, 65 \pm 5 \%$ R.H and a photoperiod of $12 \mathrm{~L}: 12 \mathrm{D}$. The pairs were checked daily and the eggs collected and observed daily until they hatched. After hatching, the neonates were transferred to muslin-covered beakers containing an ad libitum supply of A. craccivora and reared till adult emergence. The emerging adults were sexed and isolated prior to use in the experiments.

\section{(i) Reproductive Performance of H. variegata (Mate Choice: polyandry versus monogamy)}

Reproductive performance of $H$. variegata in terms of fecundity and percentage egg hatch was determined for three mating combinations. These were: (i) an initially 12-day-old virgin female was paired once daily with the same initially virgin male of the same age (monogamous with limited mating), (ii) an initially 12 -day-old virgin female was mated each day with a different virgin male of the same age as the female (i.e., male age changed with female age)(polyandrous with no-choice of mate), and (iii) an initially 12 -day-old young virgin female was kept with four same aged unmated males, thus allowing the female to choose her mate (polyandrous with mate choice).

The mating combinations were continued for five days by introducing males into the boxes with the females between 09:00 18:00 hours. The females were kept and mated in rectangular plastic boxes $(20 \times 15 \times$ $10 \mathrm{~cm})$ covered with muslin and provided with an ad libitum supply of A. craccivora on leaves of D. lablab. Balls of cotton wool soaked with water were kept in the boxes to maintain a high level of humidity. These large experimental plastic boxes were used instead of small Petri dishes so that the female ladybirds could freely select or refuse a mate by flying away. This was done to simulate field condition and avoid forced mating by males, especially in the polyandrous with mate choice combination. The four male ladybirds in the polyandrous with mate choice combination were marked ' $\mathrm{A}$ ', ' $\mathrm{B}$ ', ' $\mathrm{C}$ ' and ' $\mathrm{D}$ ' by putting one, two, three or four tiny white dots, respectively on their elytra. The number of times they were observed mating with different males was noted along with the duration of each mating. The mating frequency $(\eta)$, i.e. number of times the female mated with the same partner was listed as $0,1,2,3$ or more than 4 . After five days the females were isolated in Petri dishes $(9.0 \times 1.5 \mathrm{~cm})$ and the number of eggs they laid daily and percentage egg hatch recorded for 20 days. There were ten replicates $(n=10)$ per experiment with the female in a Petri dish constituting a replicate. Data on mating duration, fecundity and percentage egg hatch were analyzed using a one-way ANOVA and post hoc comparison of means using Tukey's test of significance in statistical software SAS.

\section{(ii) Fitness of the Progeny (Polyandry versus Monogamy)}

To determine the fitness of the progeny produced by the H. variegata in the above experiment their percentage survival and duration of development was determined. For this purpose, fifty eggs were randomly selected from the batches of eggs produced by each of the females subjected to the three mating treatments. On hatching the neonates were placed in glass beakers covered with muslin. There were ten beakers containing a maximum of five larvae each. Larvae were provided with an ad libitum supply of aphids. The duration of development from egg to adult emergence and percentage survival were recorded.

Individual fitness is likely to be affected by different aspects of growth, development and reproduction depending on the different mating combinations. A useful way of summarizing the above data is to combine measures of life attributes (viz. developmental period, fecundity and survival) in a fitness indicator. Individual fitness (r) was calculated following Sadeghi and Gilbert (2000):

$$
\mathrm{r}=[\ln (\mathrm{mV})] / \mathrm{D},
$$

where $\mathrm{m}=$ Survival $(1$ or 0$), \mathrm{V}=$ Potential fecundity, $\mathrm{D}=$ Total Developmental Time. The fitness was analyzed using a one-way ANOVA followed by post hoc Tukey's honest significance test, with a 5\% significance level in statistical software SAS (Version 9.0). The percentage survival was subjected to a Chi-square Test using SAS (Version 9.0).

\section{Results}

\section{(i) Reproductive Performance of $H$. variegata (Mate choice: polyandry versus monogamy)}

The number of mating per male, frequency $(\eta)$, replicates and mating duration and in the polyandrous mate choice combination is presented (Table 1). There is an asymmetry in the mating frequencies of the four males in each subset of the mate choice-polyandry combination, with females exhibiting mate choice and selecting particular males (Table 1$)$. There was a significant $(\mathrm{F}=$ 4.78 ; $\mathrm{P}<0.01$; d.f. 3,72$)$ increase in the duration of mating with preferred males, measured in terms of the number of times they were recorded mating. The increase in the duration of mating when regressed on the number of times they mated with an individual male is best fitted by a second degree polynomial curve $\left(y=4.825 x^{2}-9.415 x+\right.$ $206.5 ; \mathrm{R}^{2}=0.963 ; \mathrm{P}<0.001 ;$ Fig. 1$)$. The females rejected the advances of certain males by flying away or kicking. Three males did not mate (Table 1). Table 2 records the reproductive output of the female $H$. variegata in terms of fecundity and percentage egg hatch. The females that were polyandrous and able to exercise mate choice were significantly more fecund $(\mathrm{F}=42.2 ; \mathrm{P}<0.001)$ and a higher percentage of their eggs hatched $(\mathrm{F}=95.2 ; \mathrm{P}<0.001)$ followed by polyandrous females that had no choice and then monogamous females with limited mating (Fig. 2a and b). 
Table 1 Number of mating per male (x), frequency ( $\eta$, i.e. number of times the female mated with the same partner), replicates $(N=\Omega x)$ and mating duration (Mean \pm S.E.) and in the polyandrous mate choice combination.

\begin{tabular}{|c|c|c|c|}
\hline $\begin{array}{c}\text { Number of } \\
\text { matings }(\mathbf{x})\end{array}$ & $\mathbf{n}$ & $\mathbf{N}$ & Mean mating duration \\
\hline 4 and more & 7 & 29 & $247.66 \pm 8.32^{\mathrm{a}} \mathrm{min}$ \\
\hline 3 & 6 & 18 & $217.28 \pm 12.45^{\mathrm{b}} \mathrm{min}$ \\
\hline 2 & 8 & 16 & $211.50 \pm 10.16^{\mathrm{bc}} \mathrm{min}$ \\
\hline 1 & 15 & 15 & $200.54 \pm 7.51^{\mathrm{c}} \mathrm{min}$ \\
\hline None & 3 & 0 & - \\
\hline & & & $\mathrm{F}=4.78 ; \mathrm{P}<0.01 ;$ d.f. $=3,72$ \\
\hline
\end{tabular}

Values are means $\pm S D$

Tukey's test range $=3.72 ;$ d.f. $=3,72$.

Means followed by different letters are significantly different.

Table 2 The effect of monogamy, polyandry with no-choice and polyandry with mate choice on reproductive output of female $H$. variegata in terms of fecundity and percentage egg hatch.

\begin{tabular}{|l|l|l|}
\hline \multicolumn{1}{|c|}{ Combination } & \multicolumn{1}{|c|}{ Fecundity } & $\begin{array}{c}\text { Percentage } \\
\text { Egg Hatch }\end{array}$ \\
\hline 1. monogamy & $405.00 \pm 16.20^{\mathrm{a}}$ & $83.13 \pm 2.07^{\mathrm{a}}$ \\
\hline 2. polyandry without mate choice & $495.20 \pm 14.25^{\mathrm{b}}$ & $88.81 \pm 3.29^{\mathrm{b}}$ \\
\hline 3. polyandry with mate choice & $585.50 \pm 13.80^{\mathrm{c}}$ & $95.32 \pm 1.99^{\mathrm{c}}$ \\
\hline F-value & $\mathbf{4 2 . 2}$ & $\mathbf{9 5 . 2}$ \\
\hline
\end{tabular}

Values are Means \pm SD

F-values are significant at $\mathrm{P}<0.001$; Tukey's test range $=3.51$; d.f. $=$ $=2,27$

Means followed by different letters are significantly different.

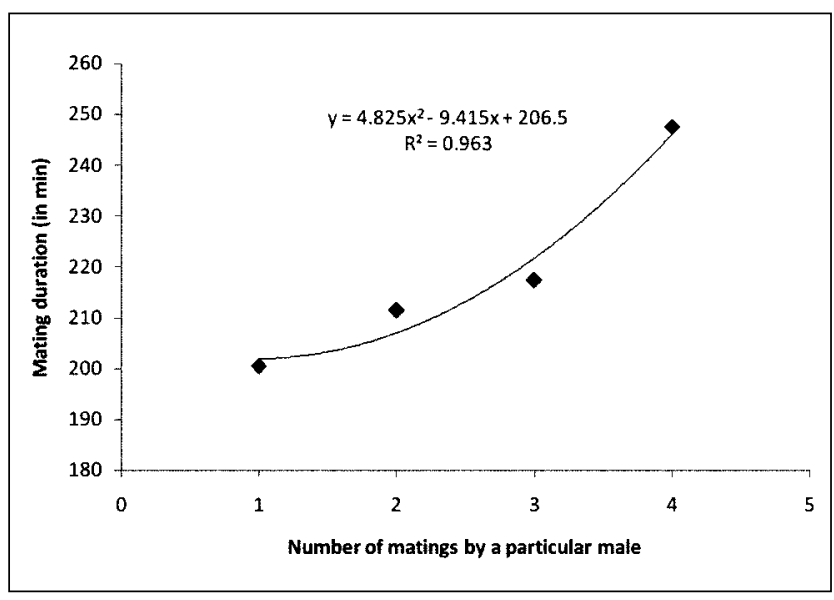

Fig. 1 Relationship between the average duration of mating and the maximum number of times a male mated in the polyandrous mate choice combination.

\section{(ii) Fitness of the Progeny (Polyandry versus Monogamy)}

The offspring produced by the polyandrous females that were able to choose their mates developed significantly faster and were fitter than those of polyandrous females that were not allowed to choose their mates and monogamous females (Table 3 ). The percentage survival of the progeny of polyandrous females that chose their mates was higher but not significantly so (Table 3 ).

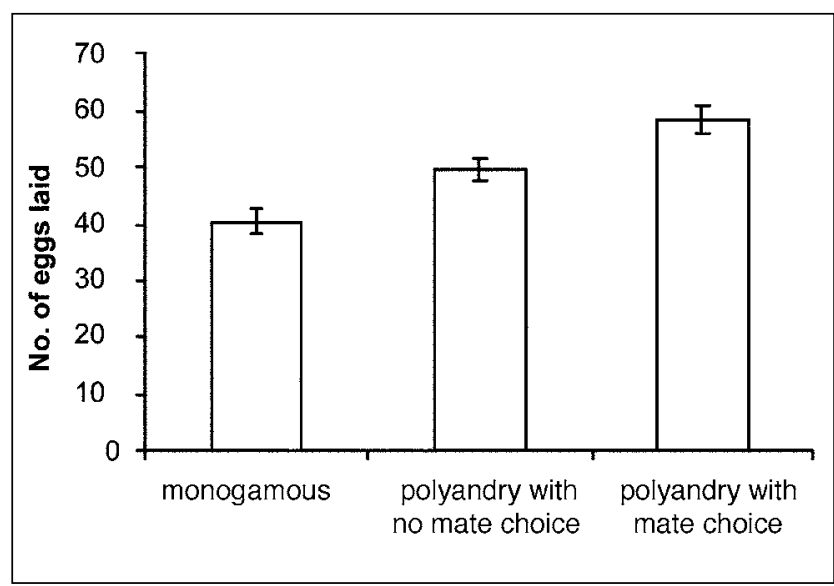

Fig. 2a Fecundity of $H$. variegata in the different mating combinations.

Table 3 Percent survival, duration of development of the larvae and fitness of the ladybird, $H$. variegata in different mating combinations.

\begin{tabular}{|l|c|c|c|}
\hline \multicolumn{1}{|c|}{$\begin{array}{c}\text { Mating } \\
\text { combinations }\end{array}$} & Survival \% & $\begin{array}{c}\text { Total dev. period } \\
\text { (in days) }\end{array}$ & Fitness \\
\hline $\begin{array}{l}\text { 1. monogamy } \\
\text { with limited } \\
\text { mating }\end{array}$ & $92.0 \%$ & $14.80 \pm 0.55^{\mathrm{c}}$ & $0.4057 \pm 0.01^{\mathrm{a}}$ \\
\hline $\begin{array}{l}\text { 2. promiscuous } \\
\text { without male } \\
\text { choice }\end{array}$ & $92.0 \%$ & $14.07 \pm 0.65^{\mathrm{b}}$ & $0.4418 \pm 0.02^{\mathrm{b}}$ \\
\hline $\begin{array}{l}\text { 3. promiscuous } \\
\text { with mate } \\
\text { choice }\end{array}$ & $98.0 \%$ & $13.32 \pm 0.39^{\mathrm{a}}$ & $0.4787 \pm 0.01^{\mathrm{a}}$ \\
\hline Analysis & $\mathrm{X}^{2}=0.130$ (N.S.) & ${ }^{*} \mathrm{~F}=18.72$ & ${ }^{*} \mathrm{~F}=495.58$ \\
\hline
\end{tabular}

Values are Mean \pm SD: N.S. $=$ Non-significant

F-values are significant at $\mathrm{P}<0.001$; Tukey's test range $=3.51$; d.f. $=$ $=2,27$

Means followed by different letters are significantly different.

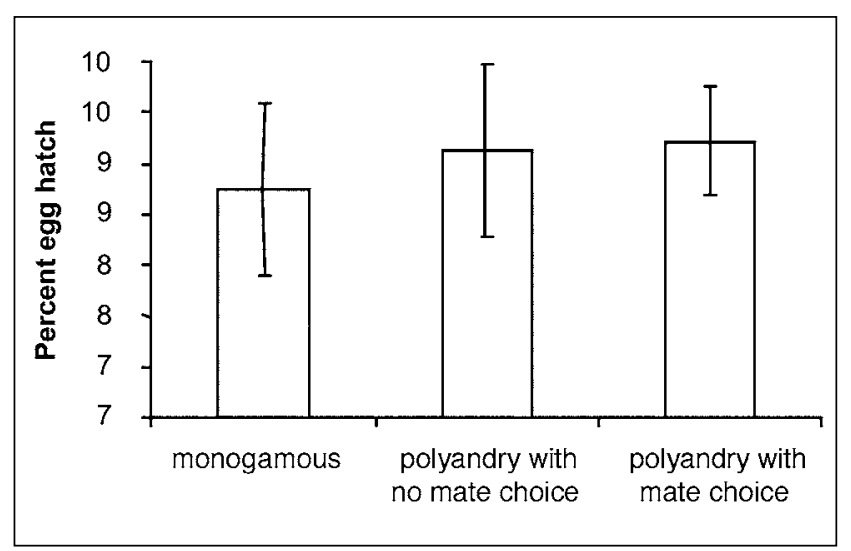

Fig. 2b Percent egg hatch of $H$. variegata females in the different mating combinations.

\section{Discussion}

The results revealed that polyandrous females had a better reproductive output and more of their progeny survived, developed more quickly and were fitter than those of monogamous females. This supports the initial 
hypothesis that polyandry is beneficial for female fitness. The polyandry was, however, more beneficial when the mate was selected by the female rather than a result of random mating. The females displayed distinct mate choice by selecting males with which they mated for longer, which resulted in an increase in the percentage of their eggs that hatched. It is suggested that polyandry may provide ladybirds with certain short- and long-term benefits (Srivastava and Omkar 2005).

The choosy females mated for longer with their preferred mates (as the frequency of males that mated four times was high). Seemingly, this is advantageous for these females as males that mated four times or more with them mated for longer than those that mated only once. Fecundity and percentage egg hatch in P. dissecta increases with increase in the duration of mating (Pervez et al. 2004). Mating duration can be considered as indicator of performance based selection. Usually, it is hypothesized that sperm has been successfully transferred if ladybirds do not eject the spermatophore after mating (Omkar and Pervez 2005). Direct sperm transfer hypothesis assumes that sperm is being transferred during the entire course of mating (Chapman 1998). This is beneficial in ladybirds where mating is costly in terms of reduced longevity and lower survival (Omkar and Mishra 2005b). Hence, prolonged mating might result in a quantitatively larger sperm transfer, which could be stored and used to fertile more eggs if mating does not occur again.

Mate choice by the females was clearly evident in the polyandry mate choice combination. Females prefer to mate with certain males as they mated more frequently with those males. The enhanced fertility that resulted supports the advantageous of females being able to select their mates. The increase in the percentage of eggs that hatched might be a result of a larger ejaculate (Savalli and Fox 1999). Omkar and Mishra (2005a) suggest that the size of the ejaculate produced by different males varies and females that mate with males that produce small ejaculates possibly indulge in polyandry in order to fulfill their sperm or nutritional requirements. In polyandrous mate choice the effects of three factors have to be taken into consideration, viz. mate choice, polyandry and multiple mating. This raises the question: Which of these factors is most important in determining the increase in reproductive fitness of the females? Numerous studies indicate it is mate choice that is most important in determining female reproductive fitness (Partridge 1980; Pitafi et al. 1995; see review Bonduriansky 2001). Similarly, it is also well accepted that polyandry in insects is advantageous (Sakaluk et al. 2002; Omkar and Mishra 2005a; Srivastava and Omkar 2005). Sakaluk et al. (2002) suggest that males provide females with nutritional benefits via nuptial gifts and ejaculates. The choice of a better mate enables females to lay more fertile eggs. Monogamous females of $H$. variegata that were not allowed to choose a mate produced significantly fewer and less viable eggs. Variation between males in ejaculate size might account for mate choice and the differences in reproductive output. The highest progeny fitness recorded was that for females that were polyandrous and able to choose their mates. Omkar and Mishra (2005a) suggest that females may get a long time evolutionary benefit in the form of fitter progeny if they are able to select better mates.

Thus, it is concluded that polyandrous choosy females produce more and better quality progeny. It is possible that females increase their chance of mating with high quality mates by mating more than once or by mating with virgin males and by so doing increase their reproductive fitness in terms of the number and quality of their offspring.

\section{Acknowledgements}

AP thanks the University Grants Commission, New Delhi, for financial assistance \{No. F.6-2(178)/2008 (MRP/ $\mathrm{NRCB})\}$ and the Department of Science and Technology for providing a travel grant (SR/ITS/02170/2010-2011).

\section{REFERENCES}

Alan K (1979) Pyrethroids and the adults of Adonia variegata. Zashchita Rastitelna 27: 17-20.

Arnqvist G, Nilsson T (2000) The evolution of polyandry: multiple mating and female fitness in insects. Anim Behav 60: 145-164.

Belikova EV, Kosaev EM (1985) The biology of the most important species of Coccinellidae and their role in controlling aphids in a cotton lucerne rotation. Biologicheskikh Nauk 5: 61-63.

Bonduriansky R (2001) The evolution of male mate choice in insects: a synthesis of ideas and evidence. Biol Rev 76: 305-339.

Bonduriansky R, Brooks RJ (1998) Copulation and oviposition behaviour of Protopiophila litigata (Diptera: Piophilidae). Can Ent 130: 399-405.

Chapman RF (1998) The Insects: Structure and Function. Fourth edition. Cambridge Univ. Press, Cambridge.

Daly M (1978) The cost of mating. Am Nat 112: 771-774.

Fan GH, Zhao JF (1988) Functional response of Adonia variegata (Goeze) (Coleop., Coccinellidae) to cotton aphids. Natur Enemies Insects 10: 187-190.

Gordon RD (1987) The first North American records of Hippodamia variegata (Goeze) (Coleoptera: Coccinellidae). J New York Ent Soc 95: 307-309.

Gumovskaya GN (1985) The coccinellid fauna. Zashchita Rastenii 11: 43.

Kalushkov PK, Dimova VI, Khristova AI (1991) Behavior of Adonia variegata (Goeze) (Coleoptera: Coccinellidae) in the search for prey. Ekologiya 24: 71-75.

Kavallieratos NG, Stathas GJ, Athanassiou CG, Papadoulis GT (2002) Dittrichia viscosa and Rubus ulmifolius as reservoirs of aphid parasitoids (Hymenoptera: 232 Aphelinidae) and the role of certain coccinellid species. Phytoparasitica 30: 231-242.

Krafsur ES, Obrycki JJ, Nariboli P (1996) Gene flow in colonizing Hippodamia variegata ladybird beetle populations. J Heredity 87: 41-47.

Majerus MEN (1994) Female promiscuity maintains high fertility in ladybirds (Coleoptera: Coccinellidae). Ent Monthly Magaz 130: 205-209. 
Natskova V (1973) The effect of aphid predators on the abundance of aphids on peppers. Rastitelna Zashchita 21: 20-22.

Nicoli G, Limonta L, Gavazzuti C, Pozzati M (1995) The role of hedges in the agroecosystem. Initial studies on the coccinellid predators of aphids. Informatore Fitopathologico 45: 7-8.

Obrycki JJ, Orr CJ (1990) Suitability of three prey species for Nearctic populations of Coccinella septempunctata, Hippodamia variegata and Propylea quatuordecimpunctata (Coleoptera: Coccinellidae). J Econ Entomol 83: 1292-1297.

Omkar, Mishra G (2005a) Evolutionary significance of promiscuity in an aphidophagous ladybird, Propylea dissecta (Coleoptera: Coccinellidae). Bull Ent Res 95: 527-533.

Omkar, Mishra G (2005b) Mating in aphidophagous ladybirds: costs and benefits. J Appl Ent 129: 432-436.

Omkar, Pervez A (2005) Mating Behaviour of an aphidophagous ladybird beetle, Propylea dissecta (Mulsant). Insect Sci 12: 37-44.

Partridge L (1980) Mate choice increases a component of offspring fitness in fruitflies. Nature 283: 290-291.

Pervez A (2002) Contribution on prey-predator relationship and reproductive biology of a colour morph of Propylea dissecta (Mulsant) (Coccinellidae: Coleoptera). Ph.D. Thesis, University of Lucknow, Lucknow, India.

Pervez A, Omkar, Richmond A (2004) The influence of age on the reproductive performance of a predatory ladybird, Propylea dissecta. J Insect Sci 4: 1-8.

Pitafi KD, Simpson R, Day TH (1995) Male mate choice for fecund females in seaweedflies. Pak J Zool 27: 233-240.

Rice WR (1996) Sexually antagonistic male adaptation triggered by experimental arrest of female evolution. Nature 38: 232-234.

Rowe L (1994) The costs of mating and mate choice in water striders. Anim Behav 48: 1049-1056.
Sadeghi E, Esmailli M (1992) Preying habits and hibernation site of Coccinella septempunctata L., Hippodamia (Adonia) variegata (Goeze), Psyllobora vigintiduopunctata L. in Karaj. J Ent Soc Iran 11: 5-8.

Sadeghi H, Gilbert F (2000) Aphid suitability and its relationship to oviposition preference in predatory hoverflies. J Anim Ecol 6: 771-784.

Sakaluk SK, Schaus JM, Eggert AK, Snedden WA, Brady PL (2002) Polyandry and fitness of offspring reared under varying nutritional stress in decorated crickets. Evolution 56: 1999-2007.

Savalli UM, Fox CW (1999) The effect of male mating history on paternal investment, fecundity and female remating in the seed beetle Callosobruchus maculatus. Funct Ecol 13: 169-177.

Singh TVK, Singh KM, Singh RN (1991) Influence of intercropping: III. Natural enemy complex in groundnut. Indian J Ent 53: 333-368.

Singh D, Singh H (1994) Predatory potentiality of coccinellids, Coccinella septempunctata Linn. and Hippodamia variegata (Goeze) over mustard aphid, Lipaphis erysimi (Kalt.). Crop Res. Hisar 7: 120-124.

Srivastava S, Omkar (2005) Short- and long-term benefits of promiscuity in the seven-spotted ladybird Coccinella septempunctata (Coleoptera: Coccinellidae). Int J Trop Insect Sci 25: 176-181.

Watson PJ (1993) Foraging advantage of polyandry for female sierra dome spiders (Linyphia litigiosa: Linyphiidae) and assessment of alternative direct benefit hypotheses. Am Nat 141: 440-465.

Watson PJ, Arnqvist G, Stallmann RR (1998) Sexual conflict and the energetic costs of mating and mate choice in water striders. Am Nat 151: 46-58.

Wheeler AG Jr, Stoops CA (1996) Status and spread of the Palaearctic lady beetles Hippodamia variegata and Propylea quatuordecimpunctata (Coleoptera: Coccinellidae) in Pensylvania, 1993-1995. Ent News 107: 291-298. 